\title{
Tau-Based Therapeutic Approaches for Alzheimer's Disease - A Mini-Review
}

\author{
Allal Boutajangout ${ }^{\mathrm{a}, \mathrm{c}-\mathrm{e}}$ Thomas Wisniewski ${ }^{\mathrm{a}-\mathrm{c}}$ \\ Departments of a Neurology, ${ }^{b}$ Pathology, ${ }^{c}$ Psychiatry and ${ }^{d}$ Physiology and Neuroscience, New York University \\ School of Medicine, New York, N.Y., USA; ${ }^{\text {C} C o l l e g e ~ o f ~ M e d i c i n e, ~ K i n g ~ A b d u l a z i z ~ U n i v e r s i t y, ~ J e d d a h, ~ S a u d i ~ A r a b i a ~}$
}

\section{Key Words}

Tau protein · Alzheimer's disease - Immunotherapy · Active immunization · Passive immunization · Aggregation ·

Glycogen synthase kinase 3

\begin{abstract}
The accumulation of aggregated, hyperphosphorylated tau as neurofibrillary tangles and neuropil threads are cardinal features of Alzheimer's disease (AD). The other lesions found in AD include amyloid plaques and congophilic amyloid angiopathy, both associated with the extracellular accumulation of the amyloid-beta $(A \beta)$ peptide. AD is the most common cause of dementia globally. Currently, there are no effective means to treat $A D$ or even to slow it down. The dominant theory for the causation of $A D$ is the amyloid cascade hypothesis, which suggests that the aggregation of $A \beta$ as oligomers and amyloid plaques is central to the pathogenesis of AD. Numerous therapies have been developed directed to $A \beta$-related pathology, in particular various immunotherapeutic approaches. So far all of these have failed in clinical trials. Recently, there has been more focus on therapy directed to tau-related pathology, which correlates better with the cognitive status of patients, compared to the amyloid burden. Immunotherapeutic targeting of tau pathology has shown great potential in treating tau pathologies in mouse models of AD. A number of studies have shown the
\end{abstract}

efficacy of both passive and active immunization. This review summarizes recent advances in therapy targeting pathological tau protein, in particular focusing on immunotherapeutic approaches which are showing great promise.

(c) 2014 S. Karger AG, Basel

\section{Introduction}

Alzheimer's disease (AD) is a progressive, neurodegenerative disorder that is characterized by extracellular amyloid-beta $(A \beta)$ deposition in the form of amyloid plaques and congophilic amyloid angiopathy, as well as intracellular neurofibrillary tangles (NFTs), containing pathological tau aggregates [1]. The neuropathological definition of $\mathrm{AD}$ requires the presence of both neuritic amyloid plaques and NFTs [1]. The most toxic species of $\mathrm{A} \beta$ and aggregated tau are thought to be oligomeric, with both of these pathologies spreading via extracellular soluble oligomers, which under some conditions have been shown to use a 'prion-like' mechanism [2]. AD is the most common cause of dementia globally, affecting approximately 36 million people currently and around 115 million by 2050 [3]. The associated costs are enormous, being estimated in the USA alone to be about USD 200 billion in 2013. Presently, available treatments have minimal or no effect on the course of disease. Numerous therapies are

\section{KARGER}

E-Mail karger@karger.com

www.karger.com/ger
(C) 2014 S. Karger AG, Basel

0304-324X/14/0605-0381\$39.50/0
Thomas Wisniewski, MD

New York University School of Medicine

Alexandria ERSP, Room 802, 450 East 29th Street

New York, NY 10016 (USA)

E-Mail thomas.wisniewski@nyumc.org 
being developed directed to $A \beta$-related pathology. Among the most advanced approaches for $A \beta$ pathology are various immunotherapeutic approaches; however, two recent phase III clinical trials of passive immunization directed to $A \beta$ failed to show any significant clinical benefit [4]. Partially as a result of these clinical failures with anti$\mathrm{A} \beta$ therapies, more focus has been placed on approaches directed to tau-related pathology.

\section{Pathogenesis of AD and Anti-A $\beta$-Directed Immunotherapy}

The dominant theory for the causation of AD has been the amyloid cascade hypothesis [5]. This theory suggests that the accumulation of $A \beta$ peptides, particularly in a highly toxic oligomeric form, is the primary pathogenic driver that downstream leads to tau hyperphosphorylation, NFT formation and ultimately synaptic and neuronal loss. Missense mutations in amyloid precursor protein or in the presenilin genes PRES 1 and 2 cause earlyonset familial forms of AD (FAD), affecting $<1 \%$ of $\mathrm{AD}$ patients [6]. The most common form of AD is late-onset sporadic $\mathrm{AD}$ (LOAD). Extensive evidence supports the amyloid cascade hypothesis in FAD patients and in models of FAD [6]. However, evidence proving that $A \beta$ is central to the pathogenesis of the common LOAD is more limited. Recent genome-wide association studies on LOAD have implicated a number of different genes involved in innate immunity, cholesterol metabolism and endocytosis, suggesting greater etiological heterogeneity [6]. Potentially conflicting evidence to the amyloid cascade hypothesis has also come from clinical and autopsy data from the initial human active vaccination trial directed to reducing amyloid plaque pathology [7]. Postmortem analysis was available from 9 subjects, which showed a considerable degree of plaque removal and reduced $\mathrm{A} \beta$ load compared to comparable nonimmunized controls [8]. Despite this, there were no differences between placebo and active immunization groups in terms of long-term survival outcome, time to severe dementia and outcome measures such as Alzheimer' Disease Assessment Scale - cognitive (ADAS-Cog), MMSE or Disability Assessment for Dementia. Several passive immunization trials are underway directed to $A \beta$ pathology; however, the two most advanced phase III trials of both bapineuzumab and solanezumab were recently reported and both failed to show overall clinical improvement or disease-modifying outcomes $[4,9]$. The lack of clinical efficacy in these trials may have been related to the im- munization having begun too late in the disease process, at a point when extensive tau pathology already exists and can progress independent of the initial trigger of $A \beta$ related pathology [4]. Alternatively, one can use this data to suggest that the amyloid cascade hypothesis is an oversimplification. A number of investigators have suggested alternative theories, whereby accumulation of aggregated, toxic forms of $\mathrm{A} \beta$ and tau are dual pathways both downstream from a common upstream pathogenic deficit [4]. In either of these scenarios it is essential for therapy to specifically address tau-related pathology to be highly effective in clinically symptomatic $\mathrm{AD}$. This is particularly important as numerous studies have shown that the degree of tau-related pathology correlates better with the degree of dementia compared to amyloid plaque burden, making tau an attractive target in $\mathrm{AD}[1]$.

\section{The Tau Protein and Tau-Directed Therapy}

Tau is a microtubule-associated protein that is primarily expressed in the cell bodies and axons of neuronal cells of the central nervous system [10]. In the central nervous system, human tau is expressed in 6 isoforms arising from alternative mRNA splicing from a single gene on chromosome $17 \mathrm{q} 21$, containing 16 exons [10]. The size range of the 6 isoforms is between 352 and 441 amino acids, which differ by the absence or presence of 29 (exon 2) or 58 (exon $2+3$ ) amino acids inserts in the amino terminal. The carboxy-terminal half of tau contains 3 or 4 semihomologous repeats of 31 or 32 amino acids, encoded by exon 10 . The repeats $(3 R, 4 R)$ correspond to the microtubule-binding region of protein tau. Tau has several phosphorylation sites, with phosphorylated tau binding microtubules with lesser affinity and/or having a greater propensity to aggregate into paired helical filaments, producing NFTs.

Given the importance of tau phosphorylation in $\mathrm{AD}$, a number of studies have tried inhibition of kinases involved in the process or the activation of protein phosphatase to dephosphorylate tau (see table 1) [11, 12]. Kinases involved in tau phosphorylation include glycogen synthase kinase 3 (GSK-3 $\beta$ ), cdk5, p38, JNK, CK and DYRK1A [11]. Lithium and valproate have been shown to inhibit GSK and when given to transgenic ( $\mathrm{Tg}$ ) models reduce tau-related pathology [13]; however, this effect was not corroborated in small clinical trials for both compounds $[14,15]$. Several small-molecule inhibitors of GSK-3 $\beta$ such as SB 216763, CHIR-98014 and SRN-003556 are in preclinical development [12]. SB 216763 was 
Table 1. Preclinical approaches

\begin{tabular}{lll}
\hline Approach & Mechanism of action & Reference \\
\hline GSK-3 inhibitors & & {$[12]$} \\
SB216763, CHIR98014 & Reduces tau phosphorylation & {$[12]$} \\
SRN-003-556 & $\begin{array}{l}\text { Reduces soluble phosphorylated and aggregated tau } \\
\text { Lithium }\end{array}$ & {$[14]$} \\
Valproate & Reduces tau pathology & {$[15]$} \\
\hline Other inhibitors & & {$[12]$} \\
HSP90 & Inhibition of tau degradation & {$[21]$} \\
\hline Active immunization & & {$[24]$} \\
Tau 379-408 (pSer396-404) & Reduces tau pathology and improves cognitive tasks & {$[25]$} \\
Tau195-231 (P202/205), & Significant decrease of tau pathology with increase of the & {$[30]$} \\
Tau207-220 (P212/214), & microglia burden & {$[26]$} \\
Tau224-238 (P231) & Reduces tau pathology & {$[27]$} \\
Y10A peptide (Ser422) & Reduces tau-related pathology & {$[29]$} \\
pBri & & \\
Passive immunization & Decreases tau pathology and functional impairments & \\
PHF1 and MC1 & Decreases tau pathology with improvement of locomotor activity & \\
DA31, MC1, PHF1 & Reduction of tau pathology & \\
Anti-tau oligomers & Reduces hyperphosphorylated tau and blocks tau aggregation & \\
\hline
\end{tabular}

shown to reduce the amount of tau phosphorylation; however, adverse effects were detected in control animals [11]. Tideglusib is another inhibitor of GSK-3 $\beta$ which was in phase IIb trials for mild-to-moderate $\mathrm{AD}$; these are now completed but the results have not been reported (www.clinicaltrials.gov). In a small pilot study tideglusib produced positive trends in MMSE, ADAS-cog, GDS and Global Clinical Assessment cognitive scales without statistical significance in the small sample of 30 patients (see table 2) [16].

Another tau pathology-directed approach is inhibition of tau aggregation [17]. The most advanced of such agents are methylene blue and its derivatives $[17,18]$. Methylene blue has a range of effects in addition to tau aggregation inhibition [12]. The first methylene blue derivative was Rember (TauRx Therapeutics Ltd.), which showed stabilization of progression of AD over 50 weeks [12]. A next generation derivative, LMTX, is currently in a phase III clinical trial.

A further strategy to reduce NFT pathology is to increase tau degradation. Tau degradation has been shown to be inhibited by Hsp 90, a chaperone protein that is involved in folding of denatured proteins. Curcumin has a wide range of activities, among which is to inhibit Hsp 90. A trial in a tau Tg model showed reductions in pathology and cognitive benefits $[19,20]$. A number of Hsp 90 in-

Tau-Based Therapeutic Approaches for AD - A Mini Review
Table 2. Clinical trials

\begin{tabular}{|c|c|c|}
\hline Approach & Mechanism of action & Reference \\
\hline Tideglusib & $\begin{array}{l}\text { Inhibitor of GSK } 3 \beta \text { (in phase IIb) - } \\
\text { completed but results not yet reported }\end{array}$ & {$[16]$} \\
\hline TauRx & Inhibits tau aggregation (in phase II) & {$[12]$} \\
\hline LMTX & $\begin{array}{l}\text { Reduces the level of aggregated and } \\
\text { misfolded tau (in phase III) }\end{array}$ & {$[12]$} \\
\hline AADvac1 & $\begin{array}{l}\text { Peptide targeting pathological tau } \\
\text { (in phase I) }\end{array}$ & $\begin{array}{l}\text { Clinical- } \\
\text { Trials.gov }\end{array}$ \\
\hline
\end{tabular}

hibitors are known; however, the targeting of a chaperone protein has the potential for adverse effects [12].

Immunotherapeutic approaches have been very successful at reducing amyloid-related pathology in $\mathrm{AD}$ models, although this approach has yet to be shown as successful in clinical trials. In part driven by the success of immune therapy in amyloid pathology reduction, our group tested the first active immunization against tau pathology in a P301L tau Tg mouse model in 2007 [21]. This model develops NFTs in several brain regions and the spinal cord. The immunization was performed with a tau fragment peptide (amino acids 379-408, with pSer396 
and 404), using alum as an adjuvant. Two groups were immunized from 2 to 5 months and from 2 to 8 months. Immunohistochemical analysis using PHF1 and $\mathrm{MC} 1$ antibodies showed a significant reduction in tau-related pathology compared to controls. In addition, an improvement in the vaccinated groups was seen on a number of sensorimotor tasks. Antibodies generated by this vaccination were found to cross the blood-brain barrier, bind to phosphorylated tau and reduce pathology without significant adverse effect [21]. Subsequently, we tested the same immunogen: tau 379-408 (pSer396 and 404) in another active immunization study using a novel mouse tau Tg model (htau/PS1), developed by one of the authors of this study (A.B.) $[22,23]$. The animals were immunized from 3-4 months of age for 4 months. A significant reduction of tau pathology was observed in the brains of vaccinated mice compared to controls, which correlated with a cognitive rescue, which was tested using three separate tasks [23]. A further active immunization study used a mixture of three peptides containing the phosphorylation epitopes: tau195-213 (P202/205), tau207-220 (P212/214) and tau 224-238 (P231) [24]. This immunization was performed in a double-mutant tau (K257T/ P301S) Tg model that develops NFT like inclusions at 6 months of age. A significant decrease of tau pathology was observed in the hippocampus, the cortex and the brain stem at 8 months after immunization which was accompanied by an increase in the microglial burden. Recently, another tau immunogen was tested containing pSer422 in THY-Tau22 Tg mice, which develop latestage hippocampal pathology and cognitive defects. The mice that were immunized for 18 weeks showed a reduction in tau pathology which correlated with improved performance on spatial memory [25]. Passive immunization with monoclonal antibodies to phosphorylated tau has also shown benefits in Tg models. The first study, conducted by our group, used the PHF1 antibody (recognizes pSer396-404 tau) in P301L tau Tg mice by intraperitoneal injections and showed a reduction in tau pathology both biochemically and immunohistochemically, in association with behavioral benefits [26]. These results were confirmed by another group using both the PHF1 and the MC1 antibodies (MC1 recognizes an abnormal tau conformation) in two tau Tg models (P301L and P301S Tg mice) [27]. A reduction of tau pathology was observed in both models as well as a reduction of neurofilament positive axonal spheroids in the spinal cord with an improvement in locomotor activity [27]. A further study compared DA31 (a pan-tau antibody), MC1 and PHF1 in P301L Tg tau mice [28]. MC1-injected mice from 7 to 10 months showed a reduction of tau-related pathology both immunohistochemically and biochemically [28]. Anti-tau oligomer antibodies which block tau aggregation have also been shown to be effective in P301S $\mathrm{Tg}$ mice; however, this study used cranial intraventricular injections, limiting its clinical translatability [29]. An additional recent novel approach is the use of active immunization that produces an immune response to both pathological $A \beta$ and tau conformers concurrently; this has been shown to be effective in a number of different $\mathrm{AD} \mathrm{Tg}$ models [30]. These various preclinical tau pathology-directed immunotherapy studies have led to the first phase I vaccine trial, AADvac1, which uses a pathology-related tau peptide conjugated to KLH for active immunization; this trial is ongoing (www.clinicaltrials.gov). At first examination it is difficult to understand how antibodies binding to a protein which is accumulating intracellularly can have beneficial effects. Recent studies have demonstrated that anti-tau antibodies can cross the blood-brain barrier, be taken up by neurons via low-affinity Fc receptors and bind to pathological tau within the endosomal/ lysosomal system [31]. In addition, evidence has shown that injections of fibrillar tau brain extract into the brains of Tg mice expressing wild-type human tau can induce the formation of human tau into filaments, as well as the spread of pathology from the site of injection into neighboring brain regions in a prion-like manner [32]. Therefore, if the spread of certain pathological forms of tau that lead to PHF pathology in AD occurs via such a mechanism, antibodies to disease-associated forms of tau would not necessarily need to enter cells in order to be effective.

\section{Conclusions}

There is a critical need to develop better treatments for $\mathrm{AD}$. It is clear from studies in AD animal models that taudirected immunotherapy and related approaches can reduce pathology and produce cognitive benefits. The disappointing results with $A \beta$-directed therapies and the knowledge that tau-related pathology correlates more directly with the cognitive status of patients makes this area of research particularly important and exciting currently. The importance of $A \beta$ and tau oligomers as the most toxic species and the growing realization that both pathologies can spread in a prion-like mechanism make these the most critical targets for novel therapies. Many questions remain, in particular related to the uncertainties regarding the etiology or etiologies of LOAD as well as what the best models might be for testing effective $\mathrm{AD}$ therapies. 
We hypothesize that the best hope for effective therapies for symptomatic AD will be approaches that reduce pathological conformers of tau alone or in combination with $\mathrm{A} \beta$ oligomers.

\section{Acknowledgments}

This manuscript was supported by NIH grants NS073502, AG20245 and AG08051, as well as by the Alzheimer's Association and the Saudi Arabian Cultural Mission (USA).

\section{References}

1 Nelson PT, Alafuzoff I, Bigio EH, Bouras C, Braak H, Cairns N, Davies P, Tredici KD, Duyckaerts C, Frosch MP, Hof PR, Hulette C, Hyman BT, Iwatsubo T, Jellinger KA, Jicha GA, Kovari E, Kukull WA, Leverenz JB, Love S, Mackenzie IR, Mann DM, Masliah E, McKee A, Montine TJ, Morris JC, Schneider JA, Sonnen JA, Thal DR, Trojanowski JQ, Troncoso JC, Wisniewski T, Woltjer RL, Beach TG: Correlation of Alzheimer's disease neuropathologic changes with cognitive status: a review of the literature. J Neuropath Exp Neurol 2012;71:362-381.

2 Ashe KH, Aguzzi A: Prions, prionoids and pathogenic proteins in Alzheimer disease. Prion 2013;7:55-59.

3 Gaugler J, James B, Johnson T, Scholz K, Weuve J: Alzheimer's Disease Facts and Figures 2013. Alzheimer's Disease Association, 2013.

4 Wisniewski T, Goni F: Immunotherapy for Alzheimer's disease. Biochem Pharmacol 2014;88:499-507.

5 Hardy J, Selkoe DJ: The amyloid hypothesis of Alzheimer's disease: progress and problems on the road to therapeutics. Science 2002;297: 353-356.

-6 Bettens K, Sleegers K, Van BC: Genetic insights in Alzheimer's disease. Lancet Neurol 2013;12:92-104.

7 Bayer AJ, Bullock R, Jones RW, Wilkinson D, Paterson KR, Jenkins L, Millais SB, Donoghue $S$ : Evaluation of the safety and immunogenicity of synthetic $A \beta 42$ (AN1792) in patients with AD. Neurol 2005;64:94-101.

$\checkmark 8$ Holmes C, Boche D, Wilkinson D, Yadegarfar G, Hopkins V, Bayer A, Jones RW, Bullock R, Love S, Neal JW, Zotova E, Nicoll JA: Longterm effects of $A \beta 42$ immunization in Alzheimer's disease: immune response, plaque removal and clinical function. Lancet 2008; 372:216-223.

9 Farlow MR, Brosch JR: Immunotherapy for Alzheimer's disease. Neurol Clin 2013;31: 869-878.

10 Yoshiyama Y, Lee VM, Trojanowski JQ: Therapeutic strategies for tau-mediated neurodegeneration. J Neurol Neurosurg Psychiatry 2013;84:784-795.

11 Tell V, Hilgeroth A: Recent developments of protein kinase inhibitors as potential $\mathrm{AD}$ therapeutics. Front Cell Neurosci 2013;7:189.

12 Anand R, Gill KD, Mahdi AA: Therapeutics of Alzheimer's disease: past, present and future. Neuropharmacology 2014;76(Pt A):27-50.

13 Engel T, Goni-Oliver P, Lucas JJ, Avila J, Hernandez F: Chronic lithium administration to
FTDP-17 tau and GSK-3 $\beta$ overexpressing mice prevents tau hyperphosphorylation and neurofibrillary tangle formation, but preformed neurofibrillary tangles do not revert. J Neurochem 2006;99:1445-1455.

14 Hampel H, Ewers M, Burger K, Annas P, Mortberg A, Bogstedt A, Frolich L, Schroder J, Schonknecht P, Riepe MW, Kraft I, Gasser T, Leyhe T, Moller HJ, Kurz A, Basun H: Lithium trial in Alzheimer's disease: a randomized, single-blind, placebo-controlled, multicenter 10week study. J Clin Psychiatry 2009;70:922-931.

15 Tariot PN, Aisen PS: Can lithium or valproate untie tangles in Alzheimer's disease? J Clin Psychiatry 2009;70:919-921.

16 Del ST, Steinwachs KC, Gertz HJ, Andres MV, Gomez-Carrillo B, Medina M, Vericat JA, Redondo P, Fleet D, Leon T: Treatment of Alzheimer's disease with the GSK-3 inhibitor tideglusib: a pilot study. J Alzheimers Dis 2013;33:205-215

17 Bulic B, Pickhardt M, Mandelkow E: Progress and developments in tau aggregation inhibitors for Alzheimer disease. J Med Chem 2013; 56:4135-4155.

18 Wischik CM, Edwards PC, Lai RY, Roth M, Harrington CR: Selective inhibition of Alzheimer disease-like tau aggregation by phenothiazines. Proc Natl Acad Sci USA 1996;93: 11213-11218

19 Giommarelli C, Zuco V, Favini E, Pisano C, Dal PF, De TN, Zunino F: The enhancement of antiproliferative and proapoptotic activity of HDAC inhibitors by curcumin is mediated by Hsp90 inhibition. Cell Mol Life Sci 2010; 67:995-1004.

20 Ma QL, Zuo X, Yang F, Ubeda OJ, Gant DJ, Alaverdyan M, Teng E, Hu S, Chen PP, Maiti P, Teter B, Cole GM, Frautschy SA: Curcumin suppresses soluble tau dimers and corrects molecular chaperone, synaptic, and behavioral deficits in aged human tau transgenic mice. J Biol Chem 2013;288:4056-4065.

-21 Asuni AA, Boutajangout A, Quartermain D, Sigurdsson EM: Immunotherapy targeting pathological tau conformers in a tangle mouse model reduces brain pathology with associated functional improvements. J Neurosci 2007;27:9115-9129.

22 Boutajangout A, Frangione B, Wisniewski T, Brion JP, Sigurdsson EM: Influence of presenilin mutation on tau pathology in novel Alzheimer's disease mouse model. Alzheimers Dement 2009;5:P445-P446.

23 Boutajangout A, Quartermain D, Sigurdsson EM: Immunotherapy targeting pathological tau prevents cognitive decline in a new tangle mouse model. J Neurosci 2010;30:1655916566.

24 Boimel M, Grigoriadis N, Lourbopoulos A, Haber E, Abramsky O, Rosenmann H: Efficacy and safety of immunization with phosphorylated tau against neurofibrillary tangles in mice. Exp Neurol 2010;224:472-485.

25 Troquier L, Caillierez R, Burnouf S, Fernandez-Gomez FJ, Grosjean ME, Zommer N, Sergeant N, Schraen-Maschke S, Blum D, Buee L: Targeting phospho-Ser422 by active tau immunotherapy in the THY-Tau22 mouse model: a suitable therapeutic approach. Curr Alzheimer Res 2012;9:397-405.

26 Boutajangout A, Ingadottir J, Davies P, Sigurdsson EM: Passive immunization targeting pathological phospho-tau protein in a mouse model reduces functional decline and clears tau aggregates from the brain. J Neurochem 2011;118:658-667.

27 Chai X, Wu S, Murray TK, Kinley R, Cella CV, Sims H, Buckner N, Hanmer J, Davies P, O’Neill MJ, Hutton ML, Citron M: Passive immunization with anti-Tau antibodies in two transgenic models: reduction of Tau pathology and delay of disease progression. J Biol Chem 2011;286:34457-34467.

-28 d'Abramo C, Acker CM, Jimenez HT, Davies P: Tau passive immunotherapy in mutant P301L mice: antibody affinity versus specificity. PLoS One 2013;8:e62402.

29 Yanamandra K, Kfoury N, Jiang H, Mahan TE, Ma S, Maloney SE, Wozniak DF, Diamond MI, Holtzman DM: Anti-tau antibodies that block tau aggregate seeding In vitro markedly decrease pathology and improve cognition in vivo. Neuron 2013;80:402-414.

30 Goni F, Herline K, Peyser D, Wong K, Ji Y, Sun Y, Mehta PD, Wisniewski T: Immunomodulation targeting both $A \beta$ and tau pathological conformers ameliorates Alzheimer's disease pathology in TgSwDI and 3xTg mouse models. J Neuroinflammation 2013;10:150.

31 Congdon EE, Gu J, Sait HB, Sigurdsson EM: Antibody uptake into neurons occurs primarily via clathrin-dependent $\mathrm{fc} \gamma$ receptor endocytosis, and is a prerequisite for acute tau clearance. J Biol Chem 2013;288:3545235465.

32 Clavaguera F, Bolmont T, Crowther RA, Abramowski D, Frank S, Probst A, Fraser G, Stalder AK, Beibel M, Staufenbiel M, Jucker M, Goedert M, Tolnay M: Transmission and spreading of tauopathy in transgenic mouse brain. Nat Cell Biol 2009;11:909-913. 